\title{
Dynamic modeling and Simulation of Electric Vehicles
}

\author{
P. Suresh Kumar, Assistant Professor, Vignan's Institute of Information and Technology, \\ Visakhapatnam \& INDIA, suresh0260@gmail.com
}

V.V. Sai Santoshi, Assistant Professor, Vignan's Institute of Engineering for Women, Visakhapatnam \& INDIA, santo.appi@gmail.com

Abstract: This paper presents the benefits of EV's with conventional IC vehicles. Along with that we discuss about various Motor drive technologies (MDT),Battery charging technologies(BCT),Energy source technologies, configurations of EV's and HEV's. Based on the dynamic modeling of EV's we reduce the tractive effort on the Electric vehicles.

\section{Keywords:- Electric vehicles (EV's), Hybrid Electric Vehicles (HEV's), Internal Combustion Engine (IC Engine)}

\section{INTRODUCTION}

It seems the population has been increasing globally to around 10 billion by 2050 . And if all these vehicles are of IC Engine type then all the cities will be covered by smog and severe air pollution. This leads to damage of health, As per Air Research Board in California almost 9000 people die due to fine air dust particles. So the only promising solution to reduce this is by using EV's and HEV's [1],[2]. So based on the benefits of EV's we study about the Dynamic modeling of Electric vehicles to develop an efficient Hybrid Electric Vehicle which consumes less energy ,more efficient, less emissions.

Electric vehicles can be classified into different types on the terms of energy sources, propulsion devices, energy carriers that are uses as medium to transfer energy to propulsion devices from energy sources.

Classification of EV's based on different input methods

\begin{tabular}{|c|c|c|c|}
\hline & Propulsion type & $\begin{array}{l}\text { Energy } \\
\text { carriers }\end{array}$ & $\begin{array}{l}\text { Energy } \\
\text { sources }\end{array}$ \\
\hline Micro Hybrid EV'S & \multirow{5}{*}{$\begin{array}{l}\text { IC Engine + } \\
\text { motor }\end{array}$} & \multirow{5}{*}{$\begin{array}{c}\text { Liquid } \\
\text { fuel+ } \\
\text { Electricity }\end{array}$} & \multirow{5}{*}{$\begin{array}{l}\text { Liquid } \\
\text { fuels+ } \\
\text { Battery }\end{array}$} \\
\hline Mild Hybrid EV'S & & & \\
\hline Full Hybrid EV'S & & & \\
\hline Plug in Hybrid EV's & & & \\
\hline Range Extended EV's & & & \\
\hline Battery EV's & \multirow{4}{*}{ Electric motor } & \multirow{3}{*}{ Electricity } & Battery \\
\hline Ultra fly wheel EV's & & & $\begin{array}{l}\text { Ultra fly } \\
\text { wheel }\end{array}$ \\
\hline Ultra capacitor EV's & & & $\begin{array}{c}\text { Ultra } \\
\text { capacitor }\end{array}$ \\
\hline Fuel cell and Battery EV's & & Hydrogen & Fuel cell \\
\hline
\end{tabular}

The configuration of a typical battery electric vehicle is explained from the below figure. A BEV consists of a battery bank which is charged directly from a grid using battery charger. The electrical energy stored is transferred to the wheels by an electric drive consists of power converter and electric machine through transmission gear system. The power converter is designed such that it carry bidirectional power flow so that it can regenerate power coming from the wheels during braking. In a BEV clutch mechanism is also not required [3], [4], [5].

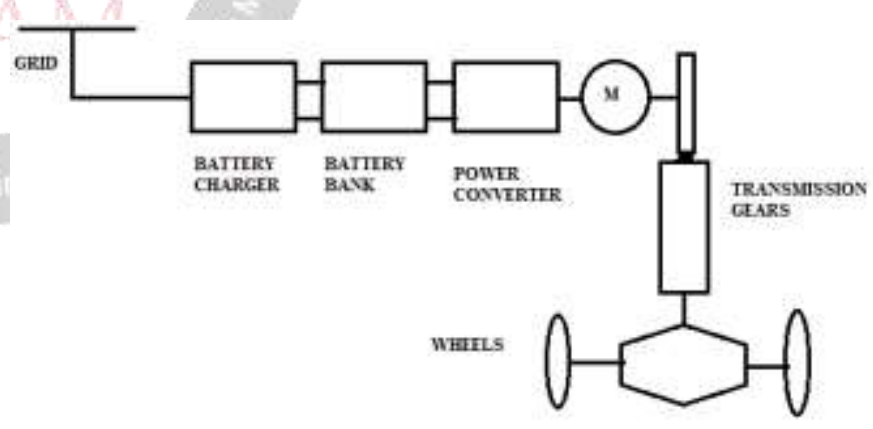

Fig 1: Typical Battery Electric Vehicle

In this configuration of a fuel cell EV's, a fuel cell is used as a source of energy which is connected to an hydrogen tank. In this a boost converter is required to boost up the voltage output from the fuel cell in order to charge the battery [3]. In this the necessity of battery bank is to allow fuel cell to operate at optimum efficiency and to support transient mechanical energy requirements of the EV's. During braking it stores the energy due to regenerative braking principle. 


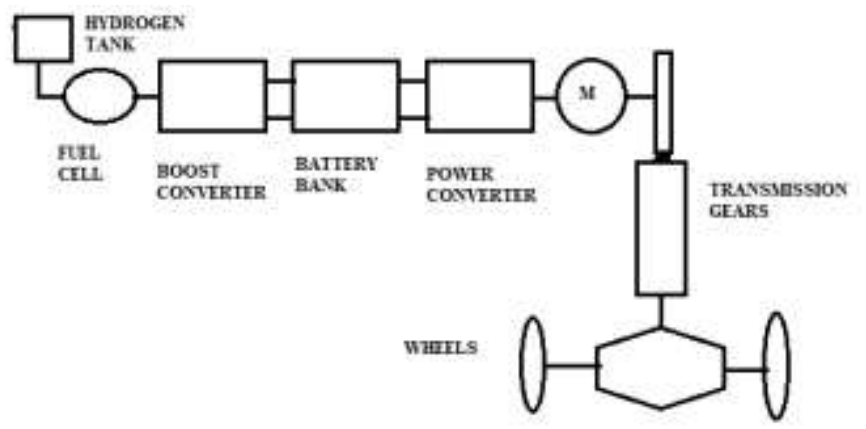

Fig 2: Typical Battery Electric Vehicle with Fuel cell

In motor drive technology the mechanical energy is transmitted to typical IC based engine vehicle. IC engine cannot operate at their own speed and torques directly so they require a clutch and multiple gear transmission system to achieve variable speeds at variable torques. So when the clutch is used the energy is transferred from IC engine to wheel with help of gear box [6]. For different speeds and torques the clutch is disengaged and the gears are changed. A typical IC engine based vehicle is shown below

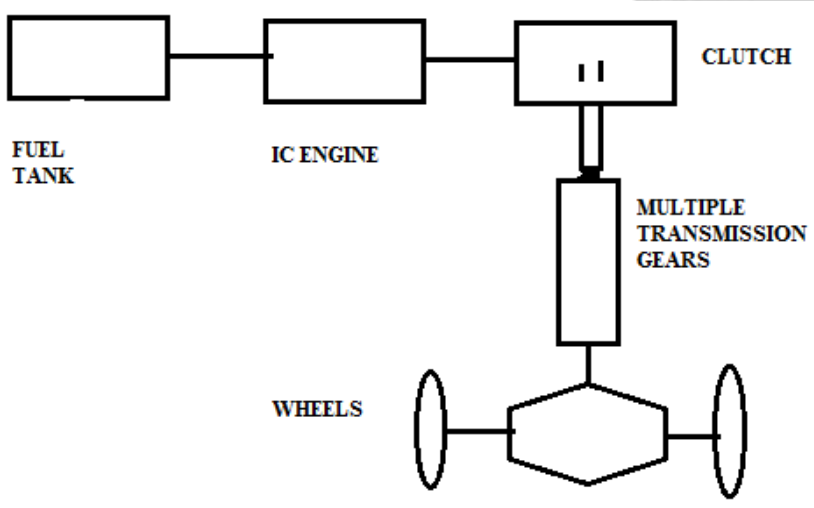

Fig 3: Motor Drive Technology

The force-speed characteristics of a 5 gear IC Engine are shown below which concludes that at low gear the torque is high and the speed is low and at high gear the torque is less and speed is more.

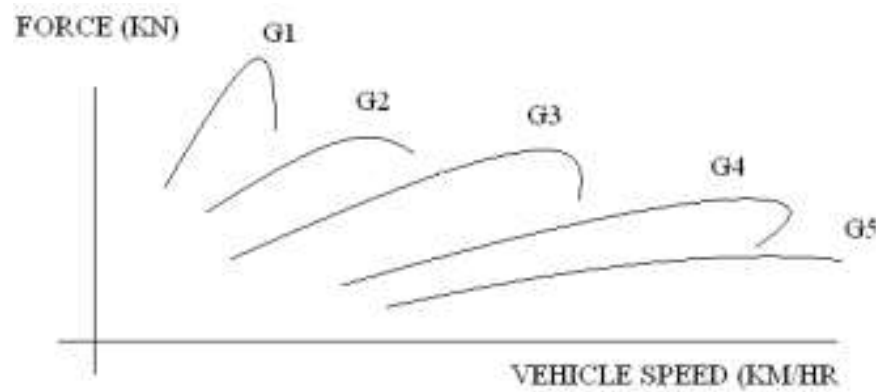

Fig 4: Force-speed characteristics of a 5 gear IC Engine

The force-speed characteristics of a battery electric vehicle with fixed gear system shows that the electric motor readily high torque at the starting and enables high speed at low torque region. This operation can be achieved without any gearing and clutch system

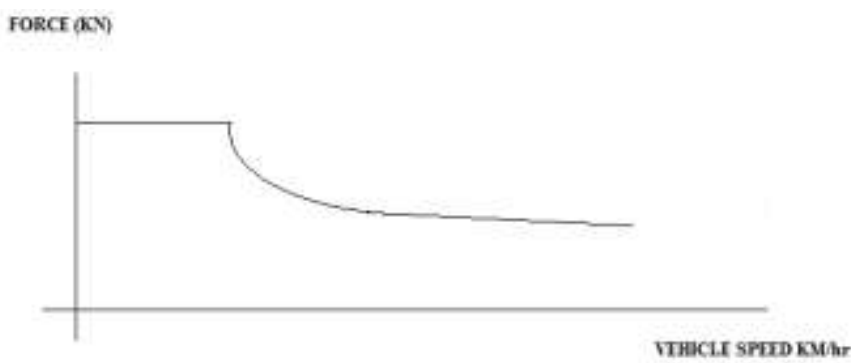

Fig 5: Force-speed characteristics of a BEV

The major requirements of a $\mathrm{EV}$ are high torque density ,high power density, wide speed range at constant torque and power regions, high efficiency, reliability and robustness .

The various energy sources used by the electric vehicles and hybrid electric vehicles are batteries, Ultra-capacitors, ultrafly wheels and fuel cells. Where batteries are electro chemical device which stores energy in electrical form, ultra capacitors store high energy in electrostatic form since the value of capacitance is very high. In ultra fly wheel high speed electric machine is used which stores energy in the form of kinetic energy [7] ,[8]. Fuel cells uses hydrogen as a fuel and stores the energy in electrical form.

In electric vehicle the various types of batteries used are lead acid, nickel cadmium, nickel zinc, zinc air, sodium nickel chloride, lithium ion etc. So we compare these batteries based on specific energy, specific power, life cycle, cost and safety.

To compare the energy sources technologies Ragone plot is the best way it is plotted between specific energy on $\mathrm{X}$-axis and specific power on $\mathrm{Y}$-axis, where the specific energy determines the driving range per charge and specific power determines the acceleration rate of the vehicle.

SPECIFIC ENERGY (WHKg)

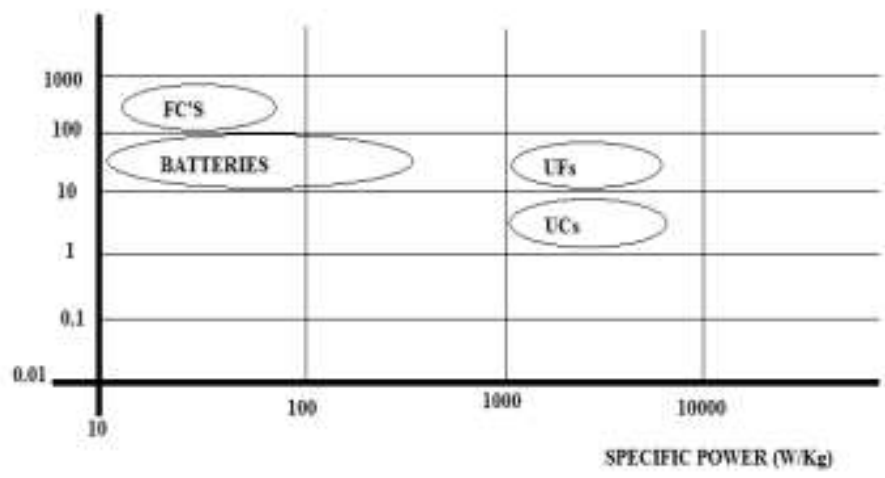

Fig 6: Ragone plot

There are four major methods of charging EV's which are mainly based on voltage level, current level, power level, time of charging [3]. In normal charging methods we use single phase system with voltage levels 110 to $240 \mathrm{v}$, current rating 13 to $20 \mathrm{Amps}$ and a power level of 2 to $4 \mathrm{KW}$. This type of methodology is generally used in homes, garages, 
residential parking places. It takes around 5 to 8 hours for charging.

Another type of charging is opportunity charging which uses three phase system with voltages 110 to $240 \mathrm{v}$ current rating of 32-80 Amps and power range of 8 to $20 \mathrm{Kw}$.

Fast charging is also one of the method for charging EV's which uses a DC system with voltage levels 200 to 450 volts ,current range of 80-200Amps and a power level of 30 to $90 \mathrm{Kw}$. It takes 20 to 30 minutes for charging.

The different methods of charging the batteries are conductive type charging and wireless charging. The wired type charging is simple, low cost, and high efficient but the major disadvantage is it requires cables to be carried and a scope of electric shocks. So we opted for wireless charging technologies which is convenient and shock proof but has high installation cost [5], [6]. In wireless power transfer there are two major methods i.e Far field strategies and near field strategies

If the vehicle is in dynamic motion then various forces act on which results in the dynamic movement of the vehicle due to Newton's second law ,the major motive force on the vehicle is obtained from traction unit and propulsion unit. The various forces which oppose the movement of the vehicle are air friction, gravitational force, and friction due to vehicle wheels. So the final acceleration of the vehicle depends on traction component and mass of all components. Vehicle dynamics is a important and integral part of vehicle design so when designing a vehicle we have a two level approach as the system is a complex and a huge system So it's a iterative process and so when we do the modeling of vehicle dynamics, there are two ways of doing it; one is longitudinal vehicle dynamics, the another is lateral vehicle dynamics.

When the vehicle is moving in one dimension we need to find the longitudinal dynamics, but when the vehicle moves in more than one dimension then lateral dynamics are to be calculated.. For a low speed vehicle, the first or the longitudinal vehicle dynamics is enough to be understood. But when we are going for very high speed operation, we have to understand the lateral vehicle dynamics as well, for good control of the vehicle and road handling.

The force propelling the vehicle forward, this is transmitted to the ground through the drive axel and wheels. So let us consider a vehicle having a mass, $M$ which is moving at velocity, $v$ and going at a slope of angle, theta. Then, the typical electric tractive effort that is required to be accomplished is equal to the force required to overcome the rolling resistance; that is the resistance offered due to tire resistance and the road resistance.

The vehicle also has to overcome the aerodynamic drag. So this is the opposing force due to air pressure. Thirdly, we all know that when we are going on a slope, let's say on a flyover or on a hill, the vehicle mass itself will act against the driving force. So this is kind of a gradient force which opposes the motion and it has to be also overcome. Secondly, if the vehicle needs to be accelerated, those forces also need to be delivered by the tractive effort. So this force is absent when vehicle is running at constant speed.

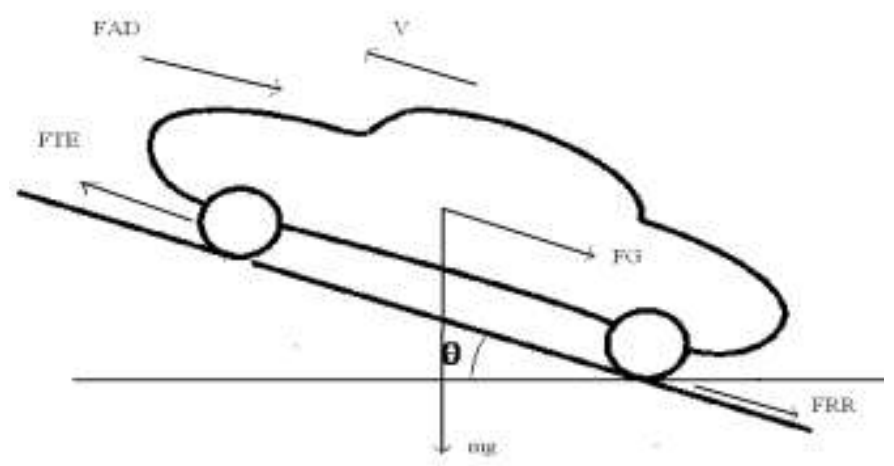

The total tractive effort which we will denote as $\mathrm{F}_{\mathrm{TE}}$ is equal to the gradient force because of the weight of the vehicle which is $\mathrm{F}_{\mathrm{G}}$

$$
\mathrm{F}_{\mathrm{G}}=\mathrm{mg} \sin \theta
$$

The opposing force due to air which is coming from a the front of the vehicle because of the velocity of the vehicle that is moving up is known as force due to air drag or aerodynamic drag.

Also the vehicle has to provide force due to tire friction or road friction which is generally termed as Frr or F rolling resistance [5] , [7]. So this tractive effort FTE has to support all these forces that is Fg which is forced to gradient, Frr which is force due to rolling resistance, FAD which is force due to aerodynamic drag and also acceleration if there is a change in vehicle speed.

The resistive force acting on the vehicle when it is moving at a velocity through air is called Aerodynamic Drag $\mathrm{F}_{\mathrm{AD}}$.

$$
\mathrm{F}_{\mathrm{AD}}=0.5 \rho \mathrm{C}_{\mathrm{D}} \mathrm{A}\left(\mathrm{V}+\mathrm{V}_{\mathrm{Air}}\right)^{2}
$$

Where $\mathrm{F}_{\mathrm{AD}}=$ Aerodynamic drag force

$$
\begin{aligned}
& \rho=\text { Density of air } \\
& C_{D}=\text { Aero dynamic drag coefficient } \\
& V=\text { Forward velocity of air } \\
& V_{\text {Air }}=\text { opposing air velocity } \\
& A=\text { Frontal Area }
\end{aligned}
$$

Aero dynamic drag coefficient depends upon the shape of the vehicle so the design of electric vehicle is important for reducing drag coefficient

The aero dynamic drag power required

$$
\mathrm{P}_{\mathrm{AD}}=\mathrm{F}_{\mathrm{AD}} * \mathrm{~V}
$$

The aero dynamic drag Energy 


$$
\mathrm{E}_{\mathrm{AD}} \alpha \mathrm{V}^{2}
$$

Rolling resistance force $\left(\mathrm{F}_{\mathrm{RR}}\right)$ the effect of the tire resistance and the road resistance on electric vehicle this force is due to the deformation of the tire on the road surface when the vehicle is moving

$$
\mathrm{F}_{\mathrm{RR}}=\mu_{\mathrm{RR}} \operatorname{mg} \cos \theta
$$

Where $\mu_{R R}=$ coefficient of rolling resistance

$$
\begin{aligned}
& \mathrm{m}=\text { mass of the vehicle } \\
& \mathrm{g}=\text { gravitational force }
\end{aligned}
$$

The gradient force acting on the vehicle when it is moving up the hill is

$$
\mathrm{F}_{\mathrm{G}}=\mathrm{mg} \sin \theta
$$

Force due to linear acceleration

$$
\mathrm{F}_{\mathrm{LA}}=\mathrm{ma}
$$

Force due to Angular acceleration

$$
\mathrm{F}_{\mathrm{AA}}=\mathrm{Ja} / \mathrm{r}^{2}
$$

The total Tractive effort of the vehicle is given as

$$
F_{T E}=F_{R R}+F_{G}+F_{A D}+F_{L A}+F_{A A}
$$

$$
\begin{aligned}
F_{T E}= & \mu_{r r} m g \cos (\theta)+m g \sin (\theta)+\frac{1}{2} \rho C_{D} A\left(v+v_{\text {air }}\right)^{2} \\
& +\left(\mathrm{m}+\frac{J}{r^{2}}\right) \frac{d v}{d t}
\end{aligned}
$$

\section{DYNAMIC EQUATION SIMULATION AT CONSTANT F TE $_{\text {Th }}$}

We have discussed about the Dynamic Equation of Electric vehicle at constant tractive effort the terminal velocity $\mathrm{V}_{\mathrm{T}}$ is given as

$$
\mathrm{V}_{\mathrm{T}}=(\mathrm{k} 2 / \mathrm{k} 1)^{0.5}
$$

Hence the time to reach the desired speed $V_{f}$ is given as

$$
\mathrm{V}_{\mathrm{f}}=0.98 * \mathrm{~V}_{\mathrm{T}}
$$

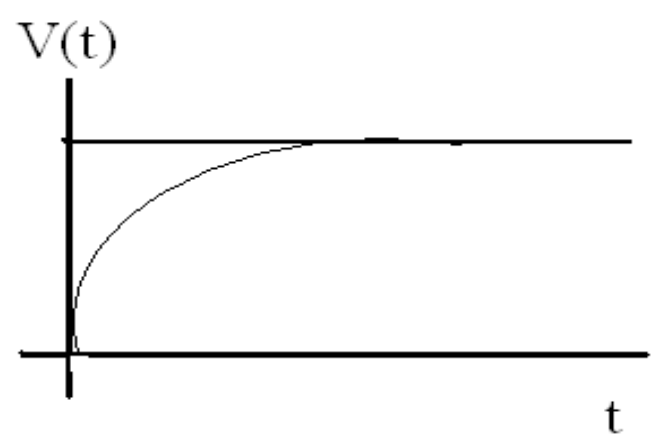

Fig 7: Velocity vs time characteristics

Similarly terminal instantaneous power is given as

$$
\mathrm{P}_{\mathrm{TE}}=\mathrm{F}_{\mathrm{TE}}(\mathrm{t}) * \mathrm{~V}(\mathrm{t})
$$

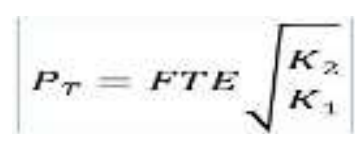

So in this let us consider a battery electric vehicle having the following parameters

Gear ratio $(\mathrm{G})=10$

Radius of the wheel $(r)=0.2 \mathrm{mt}$

Rolling friction coefficient $\left(\mathrm{mu} \_r\right.$ r $)=0.01$
Drag coefficient $(\mathrm{Cd})=0.26$

Frontal Area $(\mathrm{Ar})=2.2 \mathrm{~m}^{2}$

Mass of vehicle $(\mathrm{m})=1200 \mathrm{~kg}$

Gear efficiency (eff_gear) $=0.9$

Air density $(\mathrm{rho})=1.25 \mathrm{~kg} / \mathrm{m}^{2}$

Maximum torque $\left(T_{\max }\right)=40 \mathrm{Nm}$

Theta $=0$ degree

Wind speed $=0 \mathrm{~m} / \mathrm{sec}$

So with the parameters of the given vehicle, we can estimate the value of tractive effort force as

$$
\mathrm{F}_{\mathrm{TE}}=(\mathrm{G} / \mathrm{r}) * \text { Tmax } * \text { eff_gear }
$$

Similarly, we can also calculate the force required to... for rolling resistance force, which is

$$
\mathrm{F}_{\mathrm{rr}}=\mu_{\mathrm{rr}} \operatorname{mg} \cos \theta
$$

The constant term of the aerodynamic force is and constant $\mathrm{K} 1$ and $\mathrm{K} 2$

$$
\begin{aligned}
& \text { Const_fad }=0.5 * \text { rho } * \text { Ar } * \mathrm{Cd} \\
& \text { Constant } \mathrm{K} 1=(\text { Fte-Frr-Fg }) /(\mathrm{m}+\mathrm{m} 1) \\
& \text { Constant K2 }=\text { const_fad } /(\mathrm{m}+\mathrm{m} 1)
\end{aligned}
$$

The terminal velocity of the vehicle is

$$
\text { V_terminal }=\operatorname{sqrt}(\mathrm{K} 2 / \mathrm{K} 1)
$$

The time required to reach this velocity can be calculated by $\mathrm{t} \_\mathrm{f}=2.3 /\left(\mathrm{K} 1 * \mathrm{~V} \_\right.$terminal $)$

The maximum power this system will take is

$$
\text { P_terminal }=\left(V_{\text {_t terminal }} * \text { Fte }\right) / 1000
$$

Now the graph between velocity vs time for a battery electric vehicle at constant tractive effort

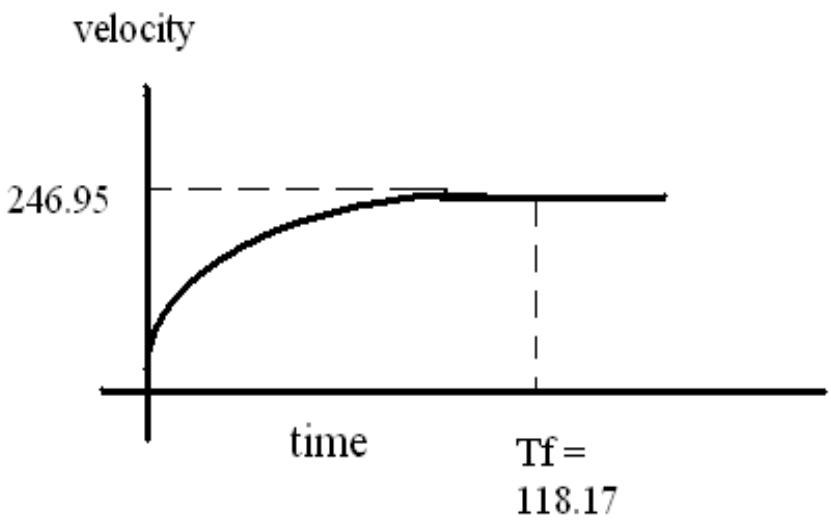

Fig 8: Velocity vs time characteristics of BEV

The graph between Distance vs time for a battery electric vehicle at constant tractive effort

\section{Distance}

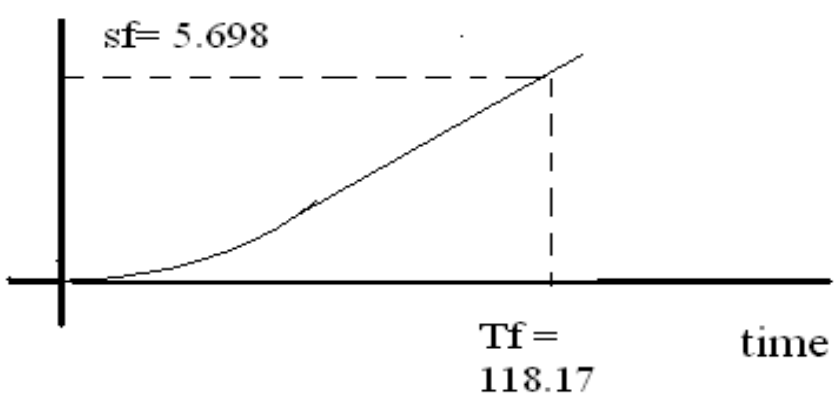

Fig 9: Distance vs time characteristics of BEV 
The graph between Power vs time for a battery electric vehicle at constant tractive effort

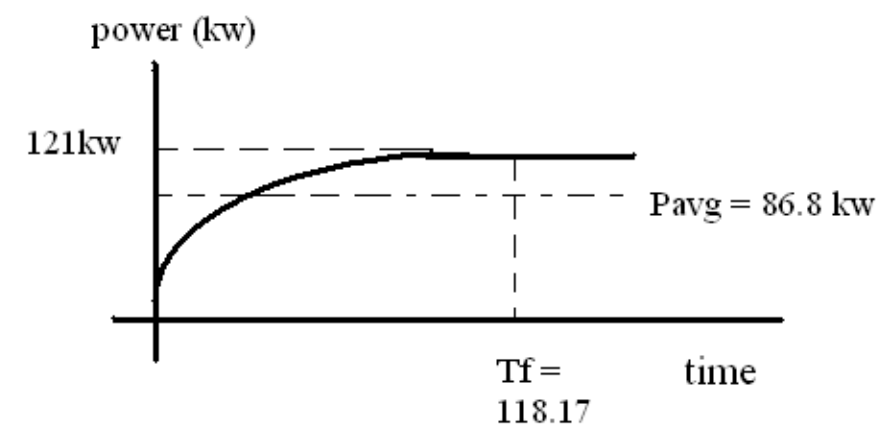

Fig 10: Distance vs time characteristics of BEV

In the previous case we assumed the slope as zero degree now we take the constant slope as 5 degree. the terminal velocity for case 1 is 246.95 , we have seen. The terminal velocity for second case is $154.3 \mathrm{~m} / \mathrm{sec}$. So it means that the terminal velocity is reduced in this case. The time to reach $98 \%$ of a terminal velocity will be 118 for the first case and almost 190 second for the case where the slope is 5 degrees. The distance travelled in this time is same, because distance is product of velocity into time [4] [7] [8]. The average power that is required in the first case was $86.8 \mathrm{KW}$ we have seen. In the second case the average power required becomes low, which is $54.23 \mathrm{KW}$. So the average power has reduced. On the other hand, the time required to reach $98 \%$ of the terminal velocity has increased in the second case.

velocity $\mathbf{m} / \mathrm{s}$

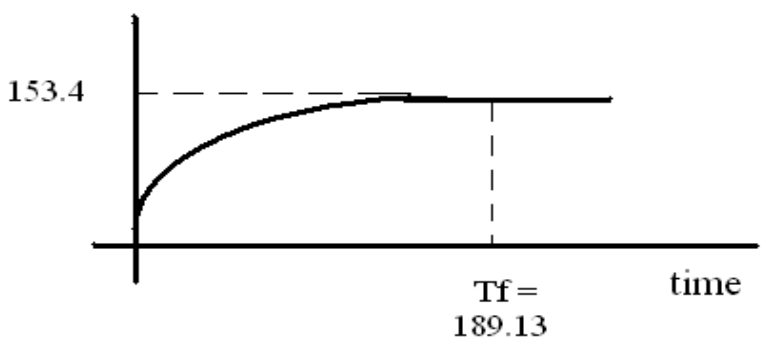

Fig 11: Velocity vs time characteristics of BEV

\section{Distance}

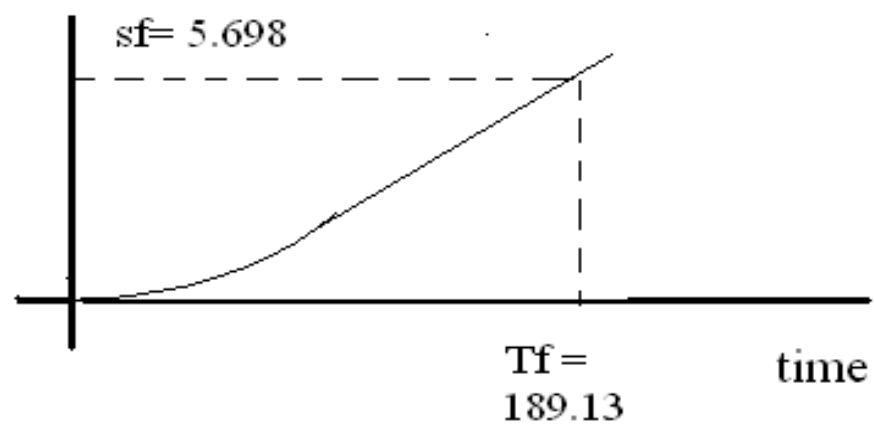

Fig 12: Distance vs time characteristics of BEV

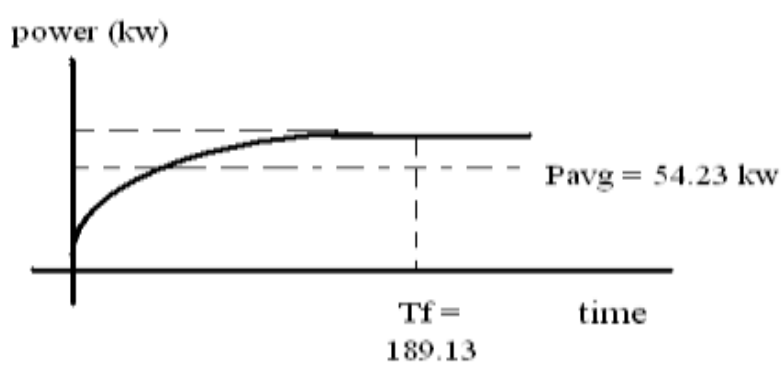

Fig 13: Power vs time characteristics of BEV

Similarly let us assume a case where the mass is reduced from $1200 \mathrm{~kg}$ to $800 \mathrm{~kg}$.So there is not much difference between the two graphs. So the acceleration is better in the case where the mass is lower. So terminal velocity are very similar. So in first case, it was 246.95 and second case it was 249.85. But since the acceleration is faster in the second case, the time required to reach the $98 \%$ of terminal velocity is lower in the second case. So it is reduced from 118 to 77.87 . The distance travelled to reach $98 \%$ of the velocity will be $5.698 \mathrm{~km}$ in the first case and it was 3.79 $\mathrm{km}$ in the second case.

\section{velocity $\mathrm{m} / \mathrm{s}$}

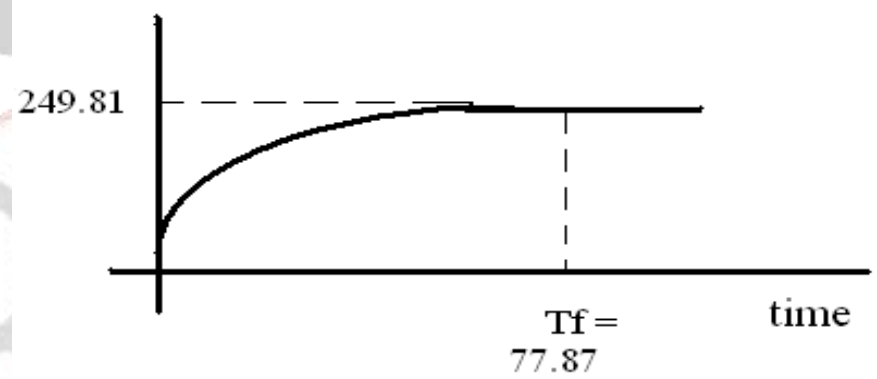

Fig 14: Velocity vs time characteristics of BEV

Distance

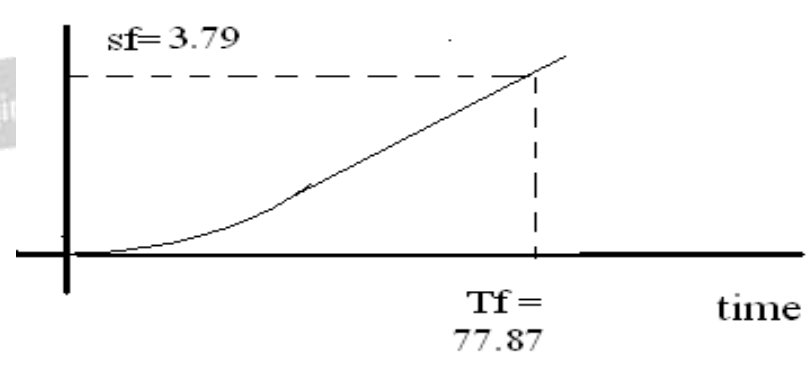

Fig 15: Distance vs time characteristics of BEV

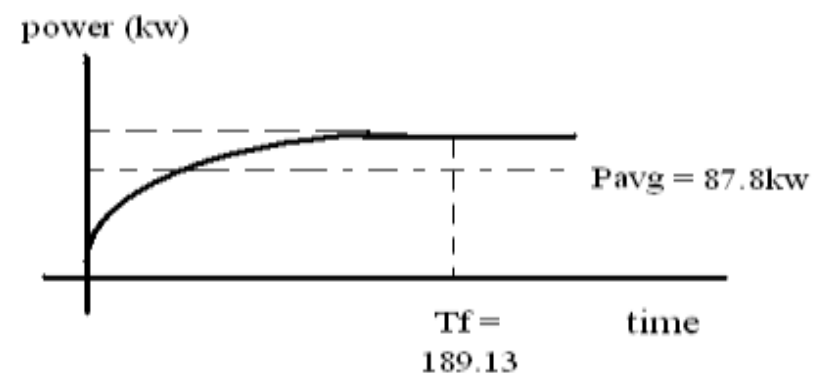

Fig 16: Distance vs time characteristics of BEV 


\section{DYNAMIC EQUATION SIMULATION AT VARIABLE $\mathbf{F}_{\mathrm{TE}}$}

Electric vehicle operate in three different modes of operation w.r.t vehicle speed i.e constant torque mode ,constant power mode, constant speed mode. So they are generally known as constant torque mode for initial acceleration, constant power mode when we want to operate the vehicle greater than the rated speed and constant speed mode where no more acceleration is required. The torque vs speed characteristics of an electric vehicle at different modes of operation is shown below

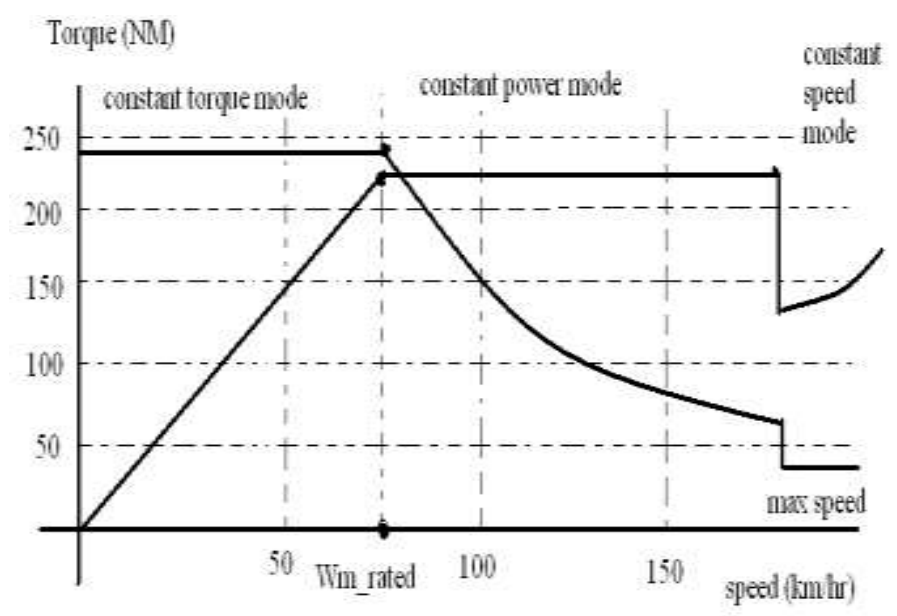

Fig 17: Torque vs Speed characteristics of BEV

So let us see these three modes of operation on a torque speed graph. So typically, let's say when the vehicle is at rest, so we are at $0 \mathrm{~km} / \mathrm{hr}$. The first thing the vehicle does is it tries to accelerate as fast as possible. So that can be done if we give a rated torque from the motor, such that the rated or the maximum tractive effort is available on the wheels [2], [4]. So this is a constant torque mode. You know, you give TM rated to the motor shaft and the vehicle speed will increase. So you can see that this is the power curve and this is the torque curve. So during this mode since the torque is constant and the speed is increasing, the power will increase linearly in this region. So power is proportional to velocity because the force is constant. So when the vehicle speed reaches the rated speed of the motor, we reach the maximum power rating of the machine. So this point is basically rated power of the machine and you cannot give the same torque at speed higher than this, because it will violate the rated power condition of the motor. So after this omega rated of the machine has reached, any further increase in speed is achieved by going in constant power mode, so this is the constant power mode. So in constant power mode, we are not violating the rated power rating of the motor, such that we will apply the torque proportional to rated power by speed of the vehicle and this is the maximum acceleration that is possible in this mode [3] ,[6]. So torque will be function of... basically torque will be function of inverse of vehicle velocity in this region. So after operating the vehicle in this mode for a definite speed, so let's say this is the maximum speed, the vehicle needs to be operated, the system will go in constant speed mode. In constant speed mode, we don't need much torque because we only need to support the losses and acceleration is 0 . So generally a very small constant torque is required and the power will increase linearly proportional to torque into the increase in velocity, so it will be almost... So these are the three regions of operation, constant torque mode up to rated speed, constant power mode up to the let's say this is the maximum speed, and constant speed mode, beyond the maximum speed.

In this we assume a battery electric vehicle with the above assumed parameters except taking Tmax $=80 \mathrm{Nm}$

Then the torque vs time graph for a $\mathrm{BEV}$ at variable input motor torque is

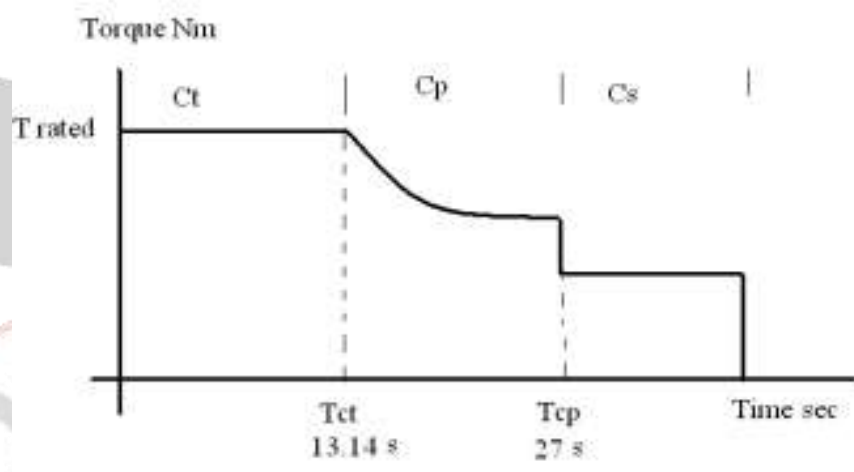

Fig 18: Torque vs time characteristics of BEV

Then the torque vs time graph for a BEV at variable input motor torque is

Distance $\mathrm{Km}$

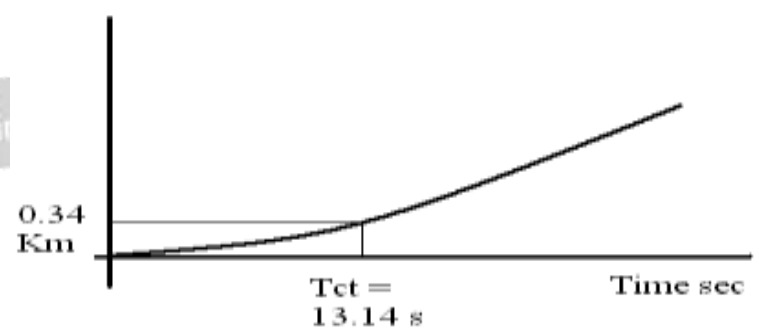

Fig 19: Distance vs time characteristics of BEV

Then the velocity vs time graph for a BEV at variable input motor torque is

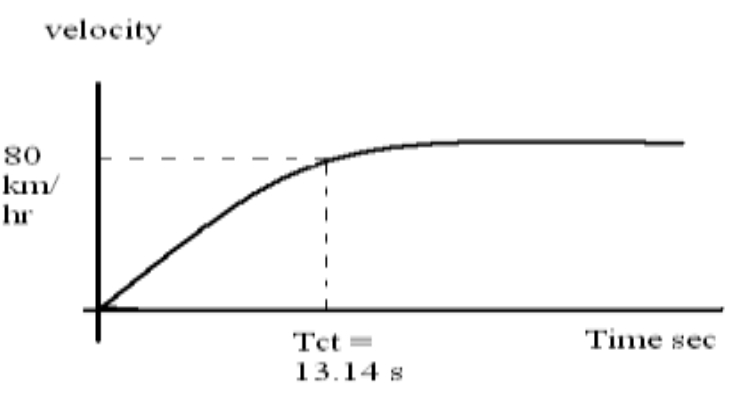

Fig 20: Velocity vs time characteristics of BEV 


\section{RESULTS AND DISCUSSION}

To study the dynamic performance of a battery electric vehicle at constant tractive effort and variable tractive effort we considered the vehicle parameters and calculated the required parameters such as velocity,distance travelled by the vehicle and average power consumed by the vehicle at constant tractive effort these results were further compared when the vehicle is moving on a upward slope of 5 degrees.

Similarly the required torque, distance travelled by the vehicle and velocity of the same vehicle is calculated at variable tractive effort.

\section{CONCLUSION}

so this kind of simulation of driving profiles, mechanical systems, and the you know the expression of constant torque, constant power, constant speed mode within those vehicle mechanical blocks will be very useful for a vehicle designer. So these kind of simulations are generally used by designers to choose the type of battery, the type of motor, the ratings of the motor, and all the subsytems within a electric vehicle.

\section{REFERENCES}

[1] IEA(2009).Technology Roadmap - Electric Vehicles and plug-in hybrid electric vehicles. Report 2009.

[2] SANDIA REPORT Energy Storage for the Electricity Grid: Benefits and Market Potential Assessment Guide. A Study for the DOE Energy Storage Systems Program, 2010

[3] Daimler, RWE (2009).Communication Protocol between Electric Vehicles and Charging Units.

[4] N.Rotering, M.Ilic: "Optimal Charge Control of Plug-In Hybrid Electric Vehicles in Deregulated Electricity Markets", IEEE Transactions on power systems, August 2011

[5] Jones , W.D., "Hybrids to the rescue [hybrid electric vehicles]", IEEE Spectrum, Vol. 40(1), 2003, pp. 70 - 71.

[6] Jones, W.D., "Take this car and plug it [plug-in hybrid vehicles]", Spectrum, IEEE, Vol. 42, Issue 7, July 2005, pp. $10-13$

[7] Chan, C.C. The Present Status and Future Trends of Electric vehicles, Science and Technology Review, Vol. 23, No.4, Feb 2005

[8] K.W.E.Cheng, "Tapped inductor for switched-mode power converters", 2 Int. Conference on Power Electronics Systems and Applications, 2006, pp. 14-20 